\title{
Por qué fueron a Rusia
}

\author{
Jorge M. REVERTE
}

Recibido: 02/05/2012

Aceptado: 20/06/2012

\section{RESUMEN}

Se esbozan en este artículo las posiciones del Ejército y la Falange en la creación de un cuerpo de voluntarios que interviniera en la invasión alemana de la URSS. A su vez, el autor se detiene en las experiencias de los voluntarios que se alistaron.

Palabras clave: División Azul, Falange, Serrano Suñer, Ridruejo.

\section{Why They Went to Russia}

\begin{abstract}
This article outlines the positions of the army and the Falange in creating a corp of volunteers for taking part in the German Invasion of the USSR. The autor describes the volunteers experiences.
\end{abstract}

Key words: Blue Division, Falange, Serrano Suñer, Ridruejo.

E1 21 de junio de 1941 en el hotel Ritz, el más lujoso de Madrid, tres hombres se reúnen para comer. Son tres importantes jerarcas del régimen franquista: Ramón Serrano Suñer, Manuel Mora Figueroa y Dionisio Ridruejo. ${ }^{1}$

Mientras degustan las delicias de la cocina del hotel, discuten sobre la situación política española, que es cualquier cosa menos tranquila. Hace pocas semanas, una crisis provocada por las disputas internas, sobre todo por la abierta confrontación entre el ejército y la Falange, ha dejado a Ridruejo sin uno de sus empleos, a Serrano en

1 RIDRUEJO, Dionisio: Materiales para una biografía (edición de Jordi Gracia), Madrid, Fundación Santander-Hispano, 2005, p. 86. 
una posición algo inestable, y a Mora Figueroa en una desairada jefatura al frente del gobierno civil de Madrid. Los tres son importantes falangistas, los tres son germanófilos, y dos de los tres piensan que Franco se está equivocando porque no ha puesto en marcha una revolución auténtica.

La idea surge de la boca de Serrano Suñer: en el caso de que se inicien las hostilidades, al margen de la posible entrada de España en la guerra general, tendría que haber tropas españolas luchando codo con codo con la Wehrmacht. Unas tropas que fueran inequívocamente falangistas. Voluntarios procedentes del partido único, del partido que tiene que impulsar aún la revolución en España frente a quienes pretenden devaluar su impulso y convertir la victoria en la guerra civil en un nuevo régimen reaccionario. Ridruejo y Mora están de acuerdo y declaran que ellos serán voluntarios en esa eventualidad.

Lo que une a los tres hombres, que mantienen posturas algo divergentes en otros terrenos, es la seguridad de que Alemania va a ganar la guerra. Y que es preciso estar a su lado. Eso, y la convicción de que hay que restarle poder al Ejército y a los partidarios de la Monarquía. Los comensales consideran que hay muchos aliadófilos en la cúpula militar. Entre ellos se cuentan el antecesor de Serrano en Asuntos Exteriores, el coronel Beigbeder y el embajador español en Londres, el duque de Alba.

Los tres tienen un problema mayor al que enfrentarse para el desarrollo feliz de sus planes falangistas y revolucionarios. Se llama ejército español. La Falange revolucionaria no ha ganado la guerra. Franco lo ha recordado hace muy pocas semanas, el 17 de abril, durante el discurso de inauguración de la Escuela Superior del Ejército. Ha sido muy claro en sus expresiones: el ejército es el vencedor de la guerra y es la columna vertebral de la Patria.

En las horas que siguen, el ejército alemán comienza la guerra en el Este, como habían previsto los comensales del Ritz, y Serrano le suelta a Franco la propuesta de formar la unidad de voluntarios para luchar junto a los alemanes "contra el enemigo común". Serrano habla con el embajador alemán, Eberhard von Stohrer, para hacerle la oferta, que es "un gesto de solidaridad... independiente de la entrada completa y total de España en la guerra al lado del Eje, que tendrá lugar en el momento apropiado". Hitler conoce pronto la noticia y acepta el ofrecimiento con "agrado y satisfacción". De modo que España no entra en la guerra, pero enviará soldados a participar en ella, y se encuentra en un estado de "beligerancia moral". Un estado peculiar, muy poco descrito en los libros anteriores a esta guerra y menos aún en los tratados de relaciones internacionales. ${ }^{2}$

Los banderines de enganche se abrirán de inmediato. Según los primeros datos, desde luego no contrastados, se apuntan más de medio millón de varones en edad militar. Las cifras más seguras se quedan en una que no es pequeña en todo caso, la de unos cuarenta mil.

¿A qué se apuntan los voluntarios que quieren hacer pagar a Rusia su acción contra España durante la guerra civil?

La discusión en el consejo de ministros alcanza momentos de tensión muy altos. Los falangistas quieren que sea una unidad de su ideología. Pero los militares no

2 MORADIELLOS, Enrique: Franco frente a Churchill, Barcelona, Península, 2005, pp. 232 y ss. 


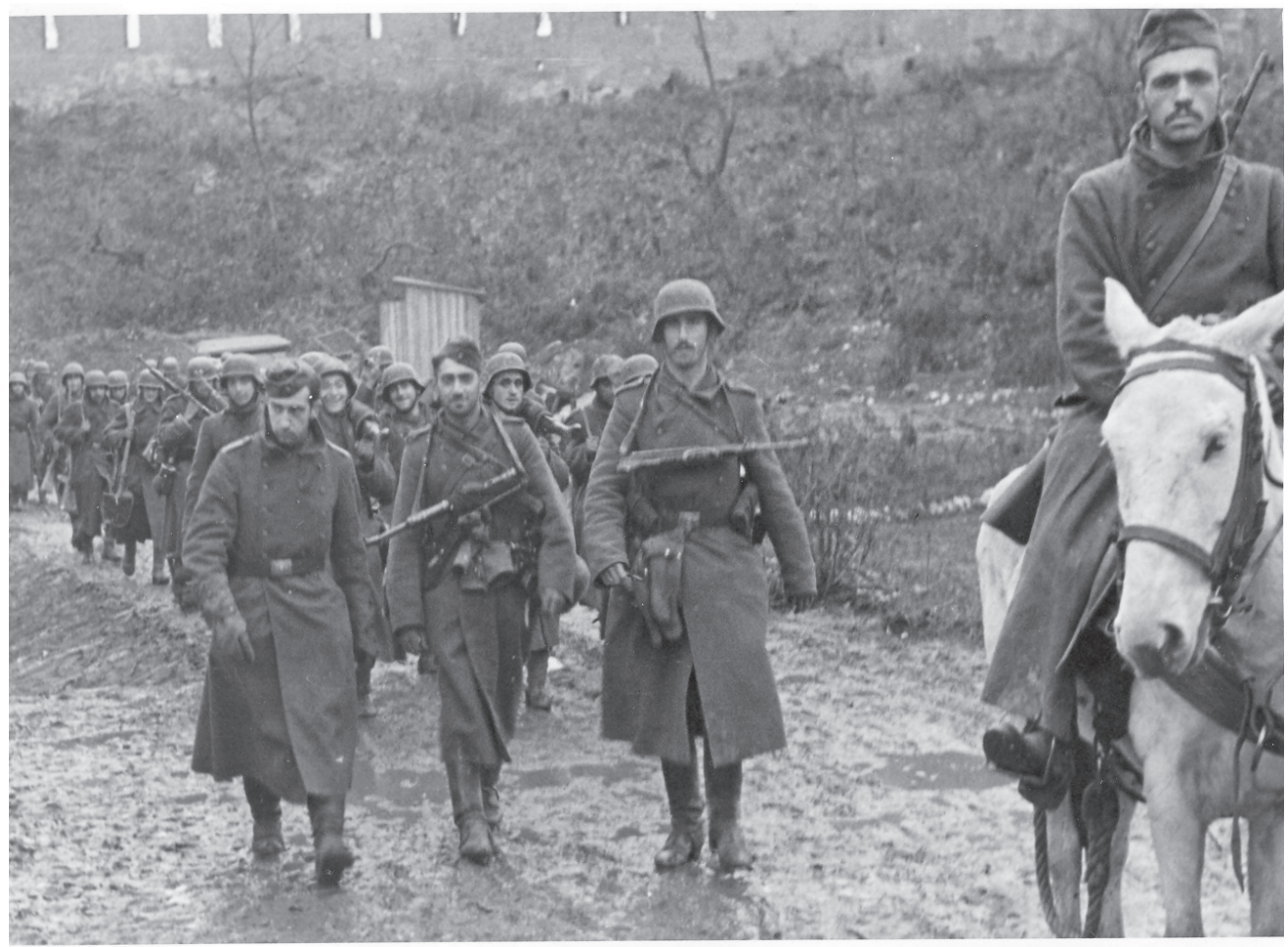

Camino del frente. Archivo Rodríguez Jiménez

quieren quedarse descolgados de la operación. Las razones son muchas. El ministro del Ejército, un gaditano de acreditado valor en combate, el general Enrique Varela, quiere que sea una división del ejército. En primer lugar, porque como muchos otros militares, está contra la posición hegemónica que los falangistas quieren obtener dentro del régimen. Pero hay una razón más contundente: no es seguro que un cuerpo de voluntarios funcione bien sin oficiales profesionales. Por mucho que se envíe a Rusia a gente que ya ha hecho una guerra, los profesionales garantizan que ésta se haga bien.

Los militares españoles se mueven en aguas turbulentas. La posición dominante parece ser la de no desear entrar en la guerra, porque no se sienten preparados, y porque hay corrientes que piensan, con acierto, que semejante decisión no sólo sería catastrófica para el país, sino que además acarrearía la inmediata subordinación de todo el Estado a la Falange, la toma del poder por el partido. Alfredo Kindelán, un hombre que no suele callarse ante Franco a la hora de expresar sus ideas, y Luis Orgaz, el general monárquico que fue decisivo en el nombramiento de Franco como jefe del Estado en 1936, son de esa opinión. ${ }^{3}$

3 TUSELL, Javier y QUEIPO DE LLANO, Genoveva: Franco y Mussolini. La política española durante la Segunda Guerra Mundial. Barcelona, Planeta, 1985, p. 87 
También piensa de esa manera el asistente personal del caudillo, su primo Francisco Franco Salgado-Araujo, que ha tenido, además, ocasión de hablar con sus colegas italianos de las desastrosas consecuencias de permitir que los fascistas manden sobre los militares. ${ }^{4}$

Pero los generales no pueden desdeñar la posibilidad de combatir codo con codo con el mejor ejército del mundo. Por supuesto, van a querer su parte en la gloria, y alcanzar el sueño de un imperio reconstruido en África y con Gibraltar recuperado. La unidad que se envíe tiene que tener un carácter militar. El argumento de mayor peso objetivo es, en todo caso, el de la capacidad de combatir bien, que sólo ellos pueden garantizar. El que va más en contra de sus deseos es obvio: si la unidad es una unidad del ejército, podrá considerarse entre los aliados que España ha entrado en guerra oficialmente al lado del Eje. Serrano y Varela llegan a mantener una discusión subida de tono al respecto, con un Franco en medio que intenta templar gaitas para que no se le resquebraje el consejo.

Hay un argumento que no se utiliza abiertamente, pero que está en la mente de todos: una división falangista sería como una división de las Waffen SS, un ejército al margen de la disciplina del ejército, cuya creación puede tener consecuencias imprevisibles. Ahora, cuando las Milicias de Falange están definitivamente domesticadas, eso significaría reproducirlas, pero en gran escala, y con el apoyo alemán.

La discusión es agria. Y se llega, al final, a un acuerdo que parece sensato: los soldados los reclutará la Falange, así como un tercio de los suboficiales. Pero los oficiales y los especialistas los va a aportar el ejército, aunque siempre serán voluntarios.

¿Y quién la va a mandar? La primera propuesta falangista es descabellada: José Antonio Girón, que es ministro de Trabajo desde hace unas semanas. Un hombre importante dentro de la organización del partido único. Un hombre cuyo currículum es el de un pistolero, un matón de los primeros tiempos de la Falange de Valladolid. Alguien que no sabe nada de estrategia ni de táctica militar, que tiene una corta experiencia en combate durante la guerra que se ha acabado hace apenas dos años, en la sierra madrileña, donde se batió con otros falangistas por la posesión del Alto del León, que ahora llaman los franquistas "de los leones" en homenaje a los combatientes de agosto de 1936.

Hay otro candidato falangista, el general Juan Yagüe, un díscolo y fogoso militar al que Franco tiene en el punto de mira por sus más que presuntas actividades conspirativas con los más pronazis del régimen. Bien relacionado con los servicios secretos alemanes, se le supone implicado en una trama radical para, en caso necesario, derrocar a Franco. Eso le costó una gran bronca y un arresto hace un año, además del puesto de ministro del Aire. ${ }^{5}$ Sus actividades clandestinas han sido poco discretas y demasiado fantásticas. Yagüe es el responsable de la matanza de Badajoz en 1936, y se las ha visto con Franco en varias ocasiones, por sus discursos obreristas o por su imprevisión en los combates de la guerra, como sucedió en la batalla del Ebro, cuando se dejó sorprender por el general Rojo en el legendario paso del río. Por mucho

4 FRANCO SALGADO-ARAUJO, Francisco: Mi vida junto a Franco, Barcelona, Planeta, 1977, p. 294.

5 TUSELL y QUEIPO DE LLANO, Franco y Mussolini ..., p. 87. 


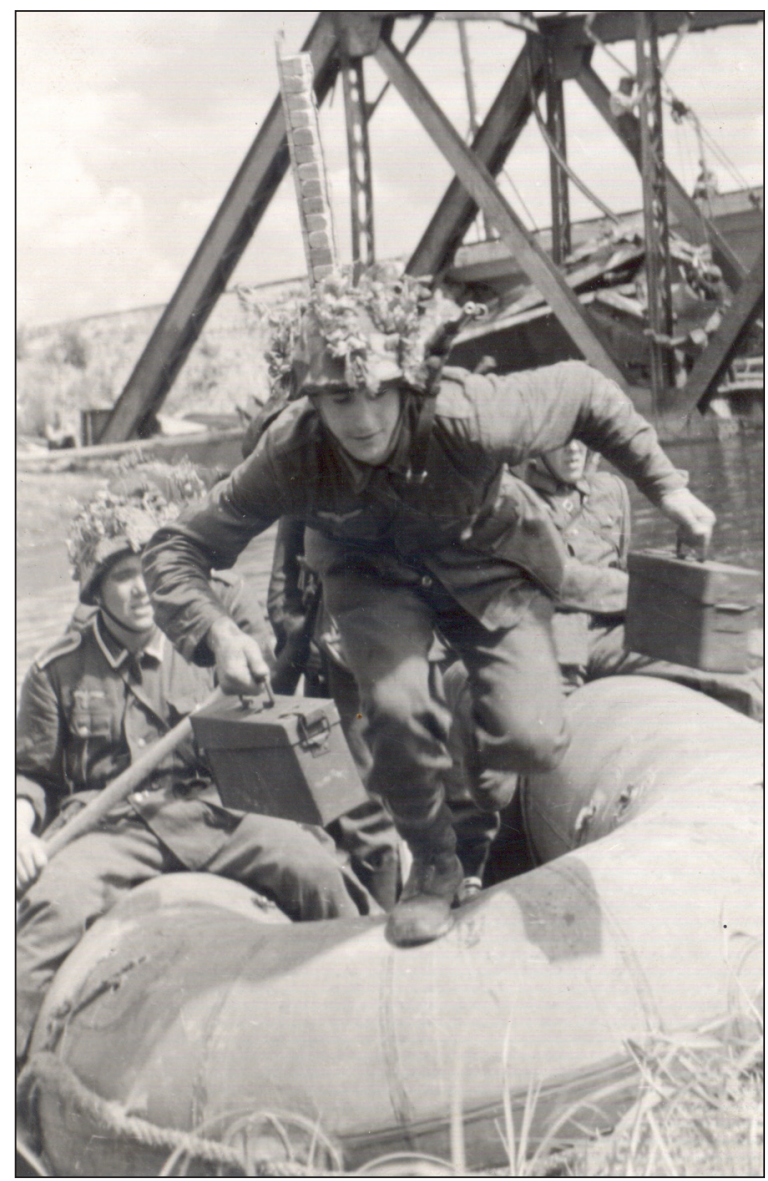

Entrenamiento. Archivo Rodríguez Jiménez

que sea el militar preferido de muchos falangistas, Franco no se fía de él lo suficiente como para encargarle algo tan delicado.

Rechazar a los dos candidatos resulta muy fácil a sus adversarios. Poner otro en su lugar, no tanto.

Pero se llega a pactar el nombre de un militar distinguido que, además, es falangista, Agustín Muñoz Grandes. Lo propone Serrano Suñer, a sugerencia de Dionisio Ridruejo. No tienen buenas relaciones personales con el general, pero es falangista y su candidatura muy difícil de rechazar, por su currículum.

Los falangistas que trabajan en el diario oficial del partido, Arriba, viven desde que la noticia les ha llegado, en un estado de paroxismo. Escriben sonoros artículos de contenido patriótico y anticomunista. Cuando se sabe que la recluta está abierta para los voluntarios, se apuntan todos.

Uno de los redactores más destacados, Vicente Cebrián llama a sus compañeros para que se apunten. José Ramón Alonso, ex combatiente del cerco de Oviedo y hom- 
bre importante en el aparato de propaganda durante toda la guerra, recibe su llamada telefónica: "Hay que apuntarse. ¡Todos a Rusia!”. Su respuesta es contundente: "Yo ya he dado bastantes tiros en la guerra".

Es de los pocos que dicen que no. Casi el noventa por ciento de la plantilla acepta el envite, incluido Daniel Martínez, que está casado, tiene dos hijos y sólo mide un metro y cincuenta y cuatro centímetros de alto. Su hermano Jesús, que pasó la guerra en el otro lado, con el Campesino, y ha estado preso en el campo de concentración de Miranda de Ebro hasta que Daniel y otros lograron sacarle, está haciendo la mili, pendiente de ir a África destinado por desafecto. La presión que recibe es la misma que recibe Juan Rojas, otro redactor que hizo la guerra en el lado republicano. Tienen que apuntarse, ellos antes que nadie. Ninguno de los dos tiene más ganas de pegar tiros, les pasa lo mismo que a Alonso, pero ellos no se pueden negar, porque los tiros que llevan acumulados los dieron en la dirección equivocada.

Al final, cuando la expedición parta hacia Rusia, sólo un clásico de la Falange, Vicente Gaceo, ellos dos y un dibujante gaditano, Joaquín de Alba, que firma como Kin en el periódico, irán hacia el frente. De Alba estuvo a punto de ser fusilado en dos ocasiones durante la guerra, hasta que pudo pasarse a la zona nacional, donde Ridruejo, que apreciaba su talento, le colocó en los servicios de propaganda. Kin no tiene que demostrar nada, porque las pasó muy mal, y luego ha prestado servicios de sobra a la causa franquista, pero siente la llamada febril, y se apunta, empujado también por los ánimos de su amigo Dionisio Ridruejo. Lo hace a pesar de que está casado y es padre de un hijo.

No tiene nada de qué hacerse perdonar, pero su expediente de depuración sigue abierto, y no se cerrará hasta dentro de tres años. Quizá no es ajeno a eso el que su hermano Nicolás, que se ocupó de su familia en Madrid mientras él se marchó a Salamanca, era comunista y un conocido dirigente de la UGT. Nicolás está en México. Se ha marchado por razones obvias.

A todos los demás entusiastas voluntarios les van a ir apareciendo motivos para desapuntarse. ${ }^{6}$

Con una excepción notable, que es la de Vicente Gaceo, uno de los fundadores de la Falange, e íntimo amigo de su desaparecido jefe, José Antonio Primo de Rivera. Sobre Gaceo se hace con frecuencia la broma de llamarle "el pequeño y valeroso Gaceo", que es la forma en que se refirió a él en una ocasión su jefe y amigo. Los dos adjetivos responden a la verdad. Fue un notorio miembro de los grupos de choque falangistas antes de julio de 1936, y es muy pequeño, apenas levanta metro y medio del suelo. Gaceo es otro de los falangistas revolucionarios que ha pasado una estancia en la cárcel por haber sido partidario de Manuel Hedilla, el hombre que se opuso a la unificación con los carlistas en 1937 y pagó por ello con una condena a muerte que no se ha cumplido.

Todos los que se desapuntan tienen muy buenos motivos, por supuesto. No se puede ir a la guerra y dejar lo demás desatendido.

A algunos falangistas les deniega el permiso la autoridad del gobierno o del partido. Dionisio Ridruejo y Manuel Mora lo consiguen. Ridruejo no tiene otra alternativa,

6 José Ramón Alonso, entrevista con el autor. 
además de porque no hizo la guerra en el frente, porque ha sido uno de los ideólogos del montaje. No puede permitir que haya la menor duda sobre su valor personal, menos aún cuando se prevé que los tiempos sean turbulentos en el trance revolucionario que se aproxima. Manuel Mora, que es un oficial retirado de la Marina, va a mantener su rango de capitán de corbeta, y a ser el ayudante del general Muñoz Grandes.

Muchos dirigentes de Falange van a ir como soldados rasos. Enrique Sotomayor, dirigente del SEU, sale de Madrid como sargento. Agustín Aznar, otro prominente falangista que ha sido responsable de las milicias antes de la unificación en 1937, llevará los humildes galones de cabo.

Aznar es médico y fundador del SEU, ha estado en la cárcel por fraguar conspiraciones contra los designios de Franco sobre la unificación de Falange y los carlistas. Pero, sobre todo, es hombre de prestigio belicoso bien labrado. Ha sido protagonista de dos acciones notorias, como la bronca entre falangistas que acabó con la vida de dos de ellos en Salamanca en un ajuste de cuentas interno. La más celebrada fue un fracaso: intentó liberar al líder de Falange, a José Antonio Primo de Rivera de su encierro en Alicante, al mando de un comando que tenía apoyo en un barco alemán.

El de Sotomayor es uno de los casos más obvios de gente que "tiene" que apuntarse. Otros falangistas de primera fila, como José Miguel Guitarte y Eduardo Rojas, que son consejeros nacionales del partido y destacados dirigentes del SEU, no esquivan su deber.

Guitarte sostiene con firmeza la importancia de Falange dentro de la estructura de la división de voluntarios. Es un intransigente partidario del carácter miliciano que debe tener la unidad combatiente. Durante los meses próximos, ya metido en el combate, seguirá haciendo hincapié en la importancia de los alféreces provisionales, falangistas y universitarios, dejando de lado a los militares profesionales que, en realidad, son los que mandan. Pero Guitarte se resiste a admitirlo, como muchos otros. El SEU debe ser la vanguardia de lo que se emprende. ${ }^{7}$

Mariano Sánchez Covisa estudia Químicas, y se apunta de los primeros. ${ }^{8}$ Es un pésimo alumno al que le llama más la acción que pegar los codos a la mesa. Su caso es muy típico: forma parte de una familia dividida por la guerra civil. Hay muchos Sánchez Covisa que han tenido que partir al exilio por su condición de republicanos destacados. Sus primos se han tenido que ir a Venezuela. Pero él es un fascista de cuerpo entero, admirador incondicional de Hitler. Y va a demostrar de lo que es capaz. ${ }^{9}$

Como es también un pésimo estudiante el que va a ser su más estrecho camarada en Rusia, Virgilio Hernández Rivadulla, un apasionado de los coches. Aunque éste tiene mayores ambiciones que Sánchez Covisa, porque a la vuelta de la División se sacará tres carreras por el sencillo método de presentarse ante el tribunal con el uniforme de Falange y una pistola al cinto. De eso presumirá, al menos.

Los dos componen un trío bien avenido con Carlos Polavieja, que se ha apuntado, como ellos, a Sanidad sólo por una razón: es la primera opción que han encontrado en el banderín de enganche, y no quieren quedarse fuera de la empresa.

7 GUITARTE, José Miguel: Hoja de Campaña, 6, Riga, 20 de noviembre de 1941.

8 Archivo General Militar de Ávila, AGMA, DEV, Caja 4994, carpeta 17.

9 Mariano Aguirre Sánchez Covisa. Entrevista con el autor. 
Ya tendrán tiempo -se dicen los tres camaradas- de pasar a Infantería. El asunto, ahora, es ser admitidos en el contingente de voluntarios. ${ }^{10}$

Los hermanos Nolla, Mario y Manuel, también son de los primeros. Mario es estudiante, aunque más aplicado que Sánchez Covisa, y está en las Milicias de Falange desde las que se enrola de acuerdo con su hermano mayor, Manuel, que está haciendo el servicio militar en Cádiz. Los dos hermanos sobrepasan la edad mínima para apuntarse, aunque deben ocultar sus deficiencias de la vista. Manuel podría haberse librado de hacer la mili porque tiene siete dioptrías en cada ojo, pero ha servido durante la guerra en zona roja, aunque sin distinguirse y eso obliga a ser discreto. La jefatura de FET de Cádiz le da un certificado en el que, de forma escueta, consta su pasado de no combatiente en zona nacional. ${ }^{11}$ A Manuel le acompañan a la estación su padre y su novia, que se llama María y es una mujer de gran belleza que ha participado, junto con otras jóvenes de su generación en las actividades de la Residencia de Señoritas, ligada a la Institución Libre de Enseñanza, ahora muy poco popular entre las nuevas autoridades.

Hay más casos de hermanos que se apuntan a la vez, casi siempre de familias muy ligadas a la Falange, como los García Noblejas, de los que se inscriben los dos que han quedado vivos después de la guerra, porque tres cayeron en el conflicto; o los Lamamié de Clairac, cuatro hermanos de origen carlista, lo que es una excepción en una unidad que se distingue por la limpieza de abolengo falangista, pese a que en su uniforme se incluye la boina roja de la tradición. O los Ruiz Vernacci, que son falangistas de primera hora.

Pero algunos hermanos acuden a la llamada con entusiasmo menos genuino. Es el caso de los hermanos Ciges, a los que les han aconsejado que se apunten a la división para así limpiar su pasado y ganar algún dinero para su madre. El pasado que tienen que limpiar los hermanos es que a su padre lo fusilaron los falangistas de Valladolid el 5 de agosto de 1936 por el delito de ser gobernador civil de la provincia de Ávila y militante de Izquierda Republicana. A toda la familia del asesinado se las han hecho pasar canutas. Los hermanos han tenido, incluso, que formar en Madrid en el gran desfile de la victoria de 1939. Los tres se han apuntado y a cada uno le ha tocado una unidad diferente. Luis Ciges se considera a sí mismo un inútil para eso de las armas, y va a conseguir que le enrolen en la cocina. ${ }^{12}$

¡No todo van a ser estudiantes! El catedrático de Derecho Fernando María Castiella, hombre de antigua militancia católica que ya tiene treinta y cuatro años, consigue meterse en la lista de admitidos. Es un hombre grande, fornido, y deseoso también de demostrar su valor. Se apunta como soldado y deja atrás una triunfal carrera de jurista. Junto con José María de Areilza ha publicado un libro de claro contenido imperial, Reivindicaciones de España, por el que le van a dar el premio nacional de Literatura mientras esté en Rusia. El libro es un auténtico compendio de los agravios que el franquismo ha incorporado a su acervo, provenientes de la mentalidad militarista que impregna a todo el nacionalismo español. Están ahí todas las razones que justifican

\footnotetext{
10 Jose Ramón Alonso. Entrevista con el autor.

11 AGMA, DEV, caja 4324, carpeta 25.

12 RIOYO, Javier: "Luis Ciges, el peor soldado del mundo", El País Semanal, 7 de febrero de 1999.
} 
la reclamación de los territorios africanos que controla Francia. Y, claro, Gibraltar. Castiella llegará a ser ministro de Asuntos Exteriores con Franco.

El día 4 de julio, a las siete de la mañana, más de cuatro mil de los voluntarios, se reúnen en torno a las ruinas de la Ciudad Universitaria para hacer la instrucción. La organización es pésima, y la actitud de los falangistas ante la disciplina militar que los profesionales quieren inculcarles es de desafío. Todos conocen más o menos la disputa que ha habido en torno a la fórmula de la constitución de la división, y la bronca que hay con el nombre de la misma, entre el oficial de División Española de Voluntarios, que ha impuesto el general Varela, y el "algo ridículo de División Azul", que ha propuesto José Luis Arrese. Para Dionisio Ridruejo, que observa a esa multitud de jóvenes con la camisa azul remangada, "a la masa falangista le irrita ya-desde ahora- (...) el husmo de la disciplina militar 'profesional'. Sin embargo, esto último no sé cómo podría eludirse." 13

El entusiasmo de los jóvenes estudiantes madrileños contrasta con el de otros sitios, como Barcelona, donde la situación se vive con la misma intensidad, pero una intensidad que afecta a un número menor de gente, y eso se nota en la escasa movilización civil. Era de esperar, porque la Falange no estaba muy implantada en Cataluña antes de la guerra. La ultraderecha en esa zona se encuadraba, sobre todo, en las filas del carlismo.

Barcelona no cubre el cupo previsto de voluntarios, pese a que todos los oficiales destinados en sus cuarteles se apuntan, y es preciso hacer una selección de los más preparados para el tipo de combate que se avecina.

La recluta en todo caso es en Cataluña muy distinta que en Madrid. Se hace, sobre todo, en los cuarteles.

La falta de voluntarios de la región se cubre con el excedente de voluntarios de Castellón y Valencia, de donde sobran. Como sobran en Murcia, en Sevilla y en Jaén.

Las plazas africanas de Ceuta y Melilla colman de oficiales, suboficiales y soldados los centros de reclutamiento. Empezando por algunos falangistas, como el mismísimo alcalde de Ceuta. Hay auténtico entusiasmo, que detecta el servicio de Información del Estado mayor del Ejército. ${ }^{14}$ Los oficiales y suboficiales van a buscar soluciones rápidas para el ascenso. Los soldados acuden por afán de aventura unos, y por hacerse perdonar la culpa de haber luchado en el lado equivocado durante la guerra civil otros. En algún cuartel se produce la afiliación de compañías completas, lo que despierta las sospechas de los seleccionadores. Porque hay una consigna: los divisionarios tienen que ser, todos ellos, gente de mucha confianza.

En Castilla la Vieja, en Valladolid, Burgos, Salamanca, la recluta es un éxito. Allí hay grandes concentraciones de falangistas, y no hay que preocuparse por los apuntados. Sobran también en Galicia y en Navarra y Guipúzcoa. En Bilbao, sin embargo, la cosa está como en Cataluña, muchos oficiales y pocos soldados.

Al final del proceso, una cuarta parte de los reclutados son madrileños, y de ellos un elevadísimo porcentaje son estudiantes universitarios, del SEU. La división va a

13 RIDRUEJO, Materiales..., p. 86.

14 Servicio Histórico Militar (S.H.M): Nota Informativa 2a Bis de Marruecos, Madrid, 12 de julio de 1941. 
tener un nivel académico superior. $\mathrm{Y}$ un componente revolucionario que se aproxima a lo que sus forjadores deseaban.

Hay un gran contraste con el ambiente general de la recluta de voluntarios en algunos lugares. Los especialistas tienen que ser, por decisión del ministro de Defensa, el general Varela, provenientes del ejército. En Vitoria se constituye, directamente en los cuarteles el batallón de zapadores, que es imprescindible para el funcionamiento de una tropa de choque.

Pero en todos los sitios cuecen habas. No siempre el entusiasmo falangista define a los que entran en las listas. Eulogio Rodríguez Pozuelo, que está haciendo la mili en el Regimiento mixto de Caballería $\mathrm{n}^{\circ} 11$, en Madrid, va a seguir con su mala suerte. A los pocos días del grito de Serrano sobre la culpabilidad de Rusia, el capitán de su escuadrón se apuntó voluntario, y se llevó, empujado por el patriotismo, a toda su tropa. Eulogio no está en condiciones de negarse, porque es un veterano del ejército de la República, ha pasado por la cárcel después de ser hecho prisionero en febrero de 1939 en Cataluña. Y estaba, ni más ni menos que en la 46 división, la del Campesino. Gracias a su astucia ha conseguido ocultar su militancia comunista, pero no su condición de combatiente. Si se negara podría acabar su mili, de la que le restan cuatro años, en África. Como en la División no hay unidades de Caballería, le toca el batallón Ciclista, que es lo más parecido. ${ }^{15}$

El sargento Dionisio García Izquierdo, natural de Guadálmez, un pueblo de Guadalajara se alista como parte del conjunto de suboficiales y de especialistas que debe aportar el ejército. No ha tenido que ser obligado, él y otros dos sargentos más, que pretenden hacer carrera en el ejército después de haber ascendido a su empleo provisional por méritos de guerra, desean probar la aventura rusa. Forman parte del regimiento de Transmisiones de El Pardo, y viven aburridos por la rutina que marca desde el toque de diana al de retreta la vida cuartelera. Los tres consiguen su admisión. Son gente veterana, que alcanza casi la treintena. ${ }^{16}$

La entrada en combate de los expedicionarios, en el flanco sur del frente de Leningrado, va a suponer un brusco cambio en la actitud de los voluntarios. Tan brusco, que la naturaleza de la propia división 250 va a cambiar con la misma rapidez.

A España llegan las noticias de que en Rusia las temperaturas llegan a veces a los 50 grados bajo cero. Y van llegando, al principio con cuentagotas y después a chorros, las noticias de los muertos.

La Falange Revolucionaria está siendo exterminada en el frente del Este. No han desfilado con las camisas arremangadas por Moscú, como presumían en sus canciones, ni consiguen avanzar un paso frente a las duras y patrióticas tropas soviéticas.

A eso, se suma la inquietud de los falangistas que han quedado en España, que ven cómo sus adversarios militares se van haciendo con el poder y cómo se aleja la perspectiva de la revolución. Serrano Suñer comienza una campaña para hacer que los más fieles de los suyos vuelvan a España sin haber cumplido su compromiso de tiempo en la lucha.

\footnotetext{
15 Entrevista del autor con Miguel Rodríguez, hijo de Eulogio. Mayo de 2010.

16 GARCÍA IZQUIERDO, Dionisio: El último divisionario en Posad, Granada, García Ispán, 2009, pp. 80 y ss.
} 
Puente sobre el Voljov, Novgorod

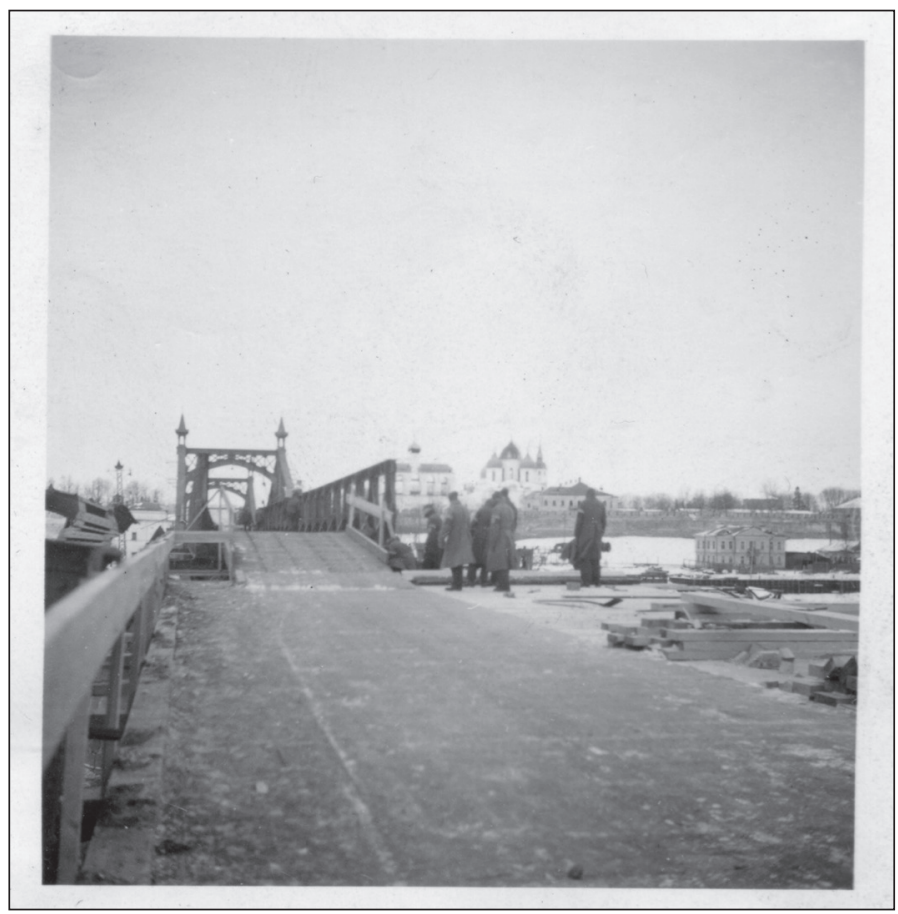

Fuente: Archivo Rodríguez Jiménez

En ellos se ha producido una mutación: la colaboración con los militares les hace apreciarse desde el punto de vista personal. Al amanecer, que viene "tardío y pausado", Ridruejo vaga de un lado a otro sin saber dónde meterse, si en el coche helado que sirve para transportar la pieza de 37 milímetros y ha utilizado durante todo el viaje para encontrar momentos de soledad, o en un pajar sin puertas ni ventanas donde se refugia toda la sección. El teniente Calvo se compadece de él y le ofrece pasar a la casita que se han arreglado los oficiales, donde arde un fuego dentro de una cocina caliente. Toma café y se seca la ropa. Puede dormir hasta el mediodía. Y se vuelve a su coche, "frío pero independiente". ${ }^{17}$

La providencial, para Ridruejo, acción del teniente Juan Calvo Izquierdo no es frecuente, porque casi todos los militares que se han apuntado a la división desprecian a los falangistas que les acompañan. Más aún si se trata de jerarcas que tienen el grado de soldados pero se comportan como si fueran generales.

Juan Calvo tiene veinticinco años y es teniente porque ha ascendido por méritos de guerra. Es natural de un pequeño pueblo de Teruel, Valdelinares, y pudo estudiar el bachillerato porque un maestro se empeñó en que dejara su destino de pastor. En la batalla del Ebro le dieron la Medalla Militar individual por su valor. Luego, después

17 RIDRUEJO, Dionisio: Los cuadernos de Rusia, 8 de octubre de 1941. 
de un par de años de paz, se apuntó a la División Española de Voluntarios, que no a la División Azul, porque no es falangista, ni simpatiza con ellos. Se ha apuntado por la fiebre de los cuarteles, por afán de aventura. ${ }^{18}$

Porque, entre los militares, esa "fiebre" no ha disminuido. La búsqueda de heroísmo, o la de ascenso y, en todo caso, la ilusión de combatir dentro del mejor ejército del mundo, son sentimientos fuertes. ${ }^{19}$

Entre los soldados que acechan Leningrado hay un joven alférez falangista llamado Pedro de la Llave García Alas. Él no le da mucha importancia a su apellido, pero es nieto de Leopoldo Alas, Clarín, el creador de Ana Ozores, La regenta, un personaje de novela que significó hace años en España lo mismo que Ana Karenina en la Rusia de su época. Leopoldo Alas murió temprano, a los cuarenta y nueve años, cuando apenas había comenzado a saborear el éxito de su gran novela. Pero había leído a los dos grandes autores de personajes femeninos del XIX, a Gustave Flaubert y a Lev Tolstoi. Flaubert murió antes de que La Regenta viera la luz, y Tolstoi no llegó a tener ninguna oportunidad de leerla porque las traducciones de Clarín todavía no habían comenzado a invadir las librerías extranjeras. De los tres autores el único que pudo leer a sus dos "rivales" fue Alas. Pedro, su nieto, se ha criado en un ambiente de reverencia hacia el abuelo, aunque sus ideas liberales no encajen nada con las de su madre, Elisa, que es la hija del novelista. En su casa se guardan como un tesoro algunos ejemplares de primeras ediciones, pero, como en tantas familias españolas, se pasa de puntillas por algunos acontecimientos, como el fusilamiento de Leopoldo Alas, el tío de Pedro, en febrero de 1937 por los militares rebeldes, con los que Pedro comparte afanes anticomunistas. ${ }^{20}$

Pedro no se plantea esas cosas. Tampoco él ha leído a Tolstoi, y desconoce si hay familiares del poeta que se escondan tras las barricadas de la Perspectiva Nevski, la avenida 25 de Octubre.

Pedro era muy joven cuando se apuntó por primera vez a la guerra, en España. En batallas como la de Navalagamella, en enero de 1939, se ha ido haciendo un hueco en el ejército, porque se ha distinguido por su valor en el combate. Y se ha venido en uno de los primeros relevos, que ha llegado al frente en junio. Para pelear contra el comunismo.

En la Hoja de Campaña de agosto lo ha contado:

(...) Ya todos lo sabéis, después de tanto triunfo de las armas alemanas desde el comienzo de la guerra, se avecinaba para Europa una época que sería como la de Santo Tomás, una Europa explicada por un mismo pensamiento. Pero quedaba aquí en el Este una incógnita para muchos y una seguridad para nosotros los que conocíamos por experiencia los métodos rusos. ¿Qué sería entonces de Europa? Se avecinaba, sin duda, una nueva invasión de los bárbaros. De que esto hubiese sido la avalancha rusa sobre Europa creo que todos los que estáis aquí tenéis las más absoluta seguridad. Por eso (...) cuando la gran Alemania salió al paso de la nueva barbarie, teníamos los españoles, los verdaderos naturalmente en el pensamiento, la culpabilidad de Rusia en

\footnotetext{
18 Francisco Calvo, hijo de Juan Calvo. Conversación con el autor, noviembre de 2010.

19 Alfonso de Ybarra. Conversación con el autor. Bilbao, 2009.

20 Pedro de la Llave. Conversación con el autor, 2004.
} 
nuestra desgracia, y uno la tuvo en los labios y fueron sus palabras el toque de clarín para la formación de la División a que con orgullo pertenecemos y por eso vinisteis los primeros y por eso os hemos venido a relevar los de ahora. (...). ${ }^{21}$

En la retórica de Pedro está lo esencial de la llamada a los militares: la lucha contra el comunismo, que representa Rusia, el apoyo decidido a Alemania, y al discurso del Orden Nuevo que hará hablar a Europa con una sola voz, como en los tiempos de Santo Tomás.

No aparecen ni los judíos ni los masones en la carta de Pedro de la Llave. Como no aparecen las referencias a la revolución social. Los militares que han llegado no están en ello, no son nazis por mucho que simpaticen con la guerra de Alemania. Vienen empujados por la entusiasmo de los cuarteles y por el impulso nacional-católico que les llevó a levantarse contra la República en 1936.

La recluta de la tropa se va haciendo más y más complicada por la pérdida de entusiasmo de los falangistas. Los nuevos soldados van a venir de las levas de las plazas africanas y de los chavales que sueñan con su propia acción heroica contra el comunismo, porque son católicos.

Como Enrique Sánchez Fraile, el voluntario católico de Picena, al que ha convencido para que venga a Rusia su confesor. Enrique viene camino de su destino a las orillas del Volchov en un tren de ganado repleto de alegres y borrachos compañeros de viaje.

Enrique ha salido de Almería el día 28 de marzo, después de una jornada de camaradería con todos los patriotas que les han despedido a él y a los demás voluntarios en la estación. La noche ha sido larga, de taberna en taberna, acompañados por el gobernador civil, el camarada Rodrigo Vivar Téllez, que ha compartido con ellos vino y cantes. Al marchar, después de un marcial y desorganizado desfile ante la banda municipal, el gobernador les ha dirigido unas ardorosas palabras:

Sois la envidia de unos y la vergüenza de otros; la envidia de aquellos a los que la Patria nos tiene clavados en puestos de responsabilidad y no podemos seguiros, y la vergüenza de aquellos a los que la Patria les exige este sacrificio y cobardemente lo rechazan. En todo cuanto se os ofrezca no veáis en mí al Jefe Provincial del Movimiento, sino a un camarada..., a un hermano. ${ }^{22}$

Benigno Cabo García es un joven de diecinueve años, nacido en Linares, Jaén, y toma la decisión de apuntarse por varias razones a la vez. Una de ellas, porque no tiene el menor deseo de hacer la mili. Con su incorporación a la división va a viajar, va a vivir aventuras, va a ser un elegido para alcanzar la gloria. Y va a ganar algún dinerillo. Las soflamas de la radio le ganan para la causa. Y se apunta en Málaga, en el cuartel de la Trinidad. Allí, "sin pensarlo demasiado, me líe la manta a la cabeza", firma todo lo que le ponen por delante, entrega tres fotografías, y ya está. Listo para el combate. $^{23}$

21 DE LA LLAVE, Pedro: Hoja de Campaña, 37, Riga, 12 de agosto de 1942.

22 SÁNCHEZ FRAILE, Enrique: Memorias inéditas.

23 CABO GARCIA, Benigno: Diario de Guerra, Linares, diario inédito, 1944. 
El que no tiene necesidad de pensárselo es José Linares García, que está en el grupo de Regulares de Caballería no 1, en Alcazarquivir, cerca de Tánger. José no es voluntario. Pertenece a la quinta de 1942 y le ha tocado África. Viene de Peñaflor, en Sevilla, dejando atrás "la gavera, el barro y los ladrillos".

Una mañana han formado su tambor y el capitán ha nombrado a ocho soldados para que pasen reconocimiento médico. Uno a uno les ha preguntado: "Tú vas a ir a la División, ¿verdad?" Y todos han dicho que sí. Qué otra cosa podían decir. Se han convertido en voluntarios para ir a Rusia. ${ }^{24}$ Para relevar a los que están desfilando por la estación de Atocha de vuelta del infierno. La fórmula que han empleado para convencerle no es muy ortodoxa, pero funciona.

Vicente Linares Linares, al que metieron "voluntario" en la división en Alcazarquivir, también recordará siempre la fecha. Viene de España, con el $16^{\circ}$ batallón de marcha. En su compañía no abundan los verdaderos voluntarios. Casi todos vienen del ejército, cribados de la misma manera que él por los oficiales. Muchos de los sargentos van de mal talante, porque se apuntaron con el entusiasmo de la primera oleada el año pasado y ahora, cuando ya no lo desean, les han recordado su impulso ya apagado, les han enseñado la firma del documento en el que pedían su incorporación a la División Azul.

En cambio, están llenos de entusiasmo los muchos seminaristas que se han presentado. Seminaristas que han dejado los hábitos de forma temporal para acabar con el judeo-bolchevismo.

Pero los jóvenes esquivan como pueden, durante el eterno viaje que les trae desde Logroño, las cuitas sobre las penalidades que les esperan, que el relato de los veteranos anuncia. Han visto los paisajes de Europa, las huertas plantadas con gran esmero, las ciudades todavía en pie, han degustado la cerveza, y algunos se han escapado unos días a Berlín. Y han jurado fidelidad al Führer en Hof, cosa de la que se ha librado José, porque no le apetece hacérselo a un país y a un jefe de Estado extranjero.

Un chaval de Peñaflor, como Vicente, que ha dejado atrás las gaveras y los ladrillos, no podía haber soñado con ver tantas cosas. Los bosques, los lagos...

Pero el horror de la guerra se sobrepone enseguida a la hermosura del paisaje. Después de la dura batalla de Krasni-Bor, en la que a la división le hacen los rusos más de mil muertos, otros tantos heridos y unos cuatrocientos prisioneros en veinticuatro horas, el deseo de volver se generaliza.

Franco necesita ya, también, traerse de vuelta a los divisionarios. Los aliados van ganando la guerra y las presiones de ingleses y norteamericanos, que amenazan con cortar el suministro de petróleo, por ejemplo, son cada vez más potentes.

El nuevo general jefe de la 250, Emilio Esteban Infantes, comienza a preparar la marcha, aunque es casi el último en enterarse de que se ha decidido su vuelta.

Como recuerdo, se deja atrás un contingente de irreductibles. Superan algo el millar, y les manda el coronel Antonio García Navarro. La unidad está compuesta por los más recalcitrantes nazis de la división, por aventureros, por legionarios ansiosos

24 LINARES, Vicente: Más que unas memorias. Hasta Leningrado con la División Azul, Madrid, Ediciones Barbarroja, 2000, p. 23. 
de pelea. Su jefe les lanza un discurso contundente: “¿Legionarios! ¿Sabéis lo que se pide en la Legión? Se pide morir". Y muchos se quedan.

Unos se quedan y otros llegan para volver de inmediato. Porque el último de los batallones de marcha, el número 27 acaba de llegar, y algunos voluntarios temen quedar mal, y otros piensan que para eso no han hecho el viaje. Los que venían forzados, los otros voluntarios a quienes oficiales del ejército de África han hecho apuntarse, comienzan un viaje de regreso en el que, por lo menos, van a volver a deleitarse con el verde paisaje de Europa. Podrán contar que han estado en la División Azul sin haber escuchado el sonido de una explosión ni haber tenido que enterrar a un camarada.

Al coronel García Navarro le indigna que muchos, casi todos, de los recién llegados vuelvan grupas. Pero, sobre todo, le indigna lo de los sargentos:

Se han marchado unos sargentos recién llegados. ¡Mejor! De vosotros, legionarios, saldrán mejores mandos de lo que ellos hubieran sido, porque su vuelta descubre mediocridades de afición a la carrera y de temperamento que no sirven para la Legión. ${ }^{25}$

Otros se tienen que ir a España obligados, por exceso de plantilla entre los de su graduación. Es el caso del capitán mallorquín Manuel Álvarez de Sotomayor, que también acaba de llegar y no consigue saciar sus ansias de combate. Sobran capitanes entre los voluntarios para la Legión. Al capitán le hacen un certificado exaltando su espíritu de sacrificio. Algo es algo. ${ }^{26}$

Hay una vuelta a la retórica más dura de los comienzos. Los que se quedan con García Navarro redoblan el mensaje de la lucha: es contra el bolchevismo, el judaísmo y la masonería. España, por medio de la Legión que sustituye a la división 250 "defiende Europa contra sus tres enemigos aliados". Que son esos. Los mismos que trajeron a Rusia a los primeros dieciocho mil voluntarios.

La Hoja de Campaña, el periódico que se ha montado en Riga como órgano oficial de la división 250, va a acompañar a los legionarios que forman la Legión Azul hasta el final de su aventura en el frente del Este. El último número se distribuirá en marzo de 1944, con una tirada de tan solo cuatrocientos ejemplares. En ese último ejemplar aparecerá la imagen a caballo del coronel García Navarro, y su encendida alocución a los supervivientes. Una crónica indignada hablará del "fatídico" día 6 de marzo cuando se obedezca la orden de disolución, obligada por las presiones aliadas.

Todavía quedarán algunos voluntarios, enrolados en unidades de las SS, a los que el ejército alemán destinará a combatir a unidades de la resistencia en los Balcanes. Uno de sus fantasiosos jefes, el teniente Miguel Ezquerra, contará en sus memorias cómo fue de los últimos en defender la cancillería de Hitler en Berlín. ${ }^{27}$

Pero hay bastantes dudas sobre la veracidad de sus acciones.

25 Hoja de Campaña, 97, 15 de diciembre de 1943.

26 NEGREIRA, Juan: Voluntarios baleares en la División Azul y Legión Azul, Palma de Mallorca, Ediciones Miramar, 1991, p. 243.

27 EZQUERRA, Miguel: Berlín a vida o muerte, Madrid, García Hispán, 1999. 